\title{
An Unusual Treatment for Massive and Refractory Bleeding after Endoscopic Retrograde Cholangiopancreatography
}

\author{
Ahmad Hormati 1,2, Farhad Zamani ${ }^{2}$, Mohammad Mohaddes ${ }^{3}$, \\ Mohammad Saeidi ${ }^{4}$, Faezeh Alemi ${ }^{5, *}$
}

1. Assistant professor of Gastroenterology and Hepatology Disease Research Center, Qom University of Medical Sciences, Shahid Beheshti Hospital, Qom, Iran

2. Gastrointestinal and Liver Disease Research Center, Iran University of Medical Sciences, Firoozgar Hospital, Tehran, Iran

3. Department of Internal Medicine, Beheshti Hospital, Qom University of Medical Sciences, Qom, Iran

4. Assistant professor of Anesthesiology, Shahid Beheshti Hospital, Qom University of Medical Sciences, Qom, Iran

5. General Practitioner, Gastroenterology and Hepatology Disease Research Center, Qom University of Medical Sciences, Shahid Beheshti Hospital, Qom, Iran

\section{* Corresponding Author:}

Faezeh Alemi, MD

Gastroenterology and Hepatology Disease Research Center, Qom University of Medical Sciences, Shahid Beheshti

Hospital, Qom, Iran

Telefax: + 982536122053

Email: faezeh.alemi@gmail.com

Received: 10 Jan. 2019

Accepted: 20 Mar. 2019

\section{Please cite this paper as:}

Hormati A, Zamani F, Mohaddes M, Saeidi M, Alemi F. An Unusual Treatment for Massive and Refractory Bleeding after Endoscopic Retrograde Cholangiopancreatography. Middle East J Dig Dis 2019;11:116-118. doi: 10.15171/mejdd.2018.137.

A 52-year-old woman with a history of laparoscopic cholecystectomy within the past 2 weeks, presented to the emergency department with abdominal pain and icter from 2 days earlier. She complained of an epigastric pain with radiation to the back, which was aggravated after taking a meal and did not change with position.

Her vital signs at admission were as below:

Blood pressure: 120:100 $\mathrm{mmHg}$, pulse rate: 68 per minute, respiratory rate: 14 per minute, body temperature from oral root: $36.7^{\circ} \mathrm{C}$.

In general appearance she looked ill and her sclera was icteric. In physical examination of the abdomen, epigastric tenderness was noticed. There were no signs of guarding and rigidity.

Description of previous problems indicated no previous hemorrhage, coagulation disorder, or taking of a specific drug.

Her laboratory findings at admission are summarized in table 1.

With respect to her clinical condition and a suspicious common bile duct (CBD) stone, magnetic resonance cholangiopancreatography (MRCP) was performed, which showed a dilated $\mathrm{CBD}$ with a diameter of $10 \mathrm{~mm}$ and a CBD stone with a diameter of $6 \mathrm{~mm}$ that was an indication for endoscopic retrograde cholangiopancreatography (ERCP) (figure 1).

During ERCP, severe bleeding occurred following sphincterotomy for removing the stone. Initial treatment was performed by sclerotherapy but re-bleeding occurred for 3 times, at 8, 12, and 24 hours after ERCP, of them the third one led to hemodynamic instability. After resuscitation with intravenous normal saline and fresh frozen plasma (FFP) infusion, she underwent endoscopic treatment. All efforts including local injection of normal saline, injection of epinephrine, argon plasma coagulation (APC), and hemoclip failed to control the bleeding. A full-cover stent was placed inevitably and saline irrigation continued so that the pressure effect of the stent on the ampulla of Vater and the site of bleeding might stop the hemorrhage (figure 2). The hemorrhage fortunately stopped and the patient was transferred to intensive care unit (ICU). No complication arose 
Table 1: Laboratory findings at admission

\begin{tabular}{lccc}
\hline Laboratory parameter & Measured value & Normal values & Measuring unit \\
\hline Amylase & 69 & $<100$ & $\mathrm{IU} / \mathrm{L}$ \\
\hline LDH & 683 & $122-222$ & $\mathrm{IU} / \mathrm{L}$ \\
\hline SGOT & 141 & $10-35$ & $\mathrm{IU} / \mathrm{L}$ \\
\hline SGPT & 172 & $10-45$ & $\mathrm{IU} / \mathrm{L}$ \\
\hline ALP & 324 & $98-279$ & $\mathrm{IU} / \mathrm{L}$ \\
\hline Total bilirubin & 6.3 & $0.2-1.2$ & $\mathrm{mg} / \mathrm{dL}$ \\
\hline Direct bilirubin & 5.7 & $0.1-0.4$ & $\mathrm{mg} / \mathrm{dL}$ \\
\hline Total CPK & 31 & $10-450$ & $\mathrm{IU} / \mathrm{L}$ \\
\hline BUN & 11.2 & $6-20$ & $\mathrm{mg} / \mathrm{dL}$ \\
\hline Creatinine & 0.5 & $0.5-1.2$ & $\mathrm{mg} / \mathrm{dL}$ \\
\hline BS & 141 & $<200$ & $\mathrm{~g} / \mathrm{dL}$ \\
\hline P & 1.8 & $2.5-4.5$ & $\mathrm{mg} / \mathrm{dL}$ \\
\hline Na & 136 & $135-145$ & $\mathrm{mEq} / \mathrm{L}$ \\
\hline $\mathrm{K}$ & 3.9 & $3.6-5$ & $\mathrm{mEq} / \mathrm{L}$ \\
\hline LDH; Lactate dehydrogenase, SGOT; Serum glutamic oxaloacetic transaminase, SGPT; Serum glutamic pyruvic transaminase, ALP; Alkaline phosphatase, CPK; Creatine phosphokinase, BUN;
\end{tabular}
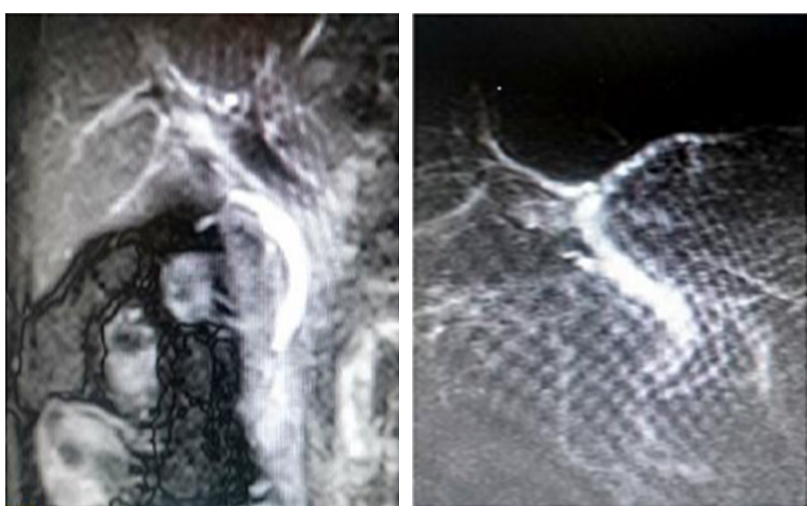

Fig.1: Magnetic resonance cholangiopancreatography shows a dilated common bile duct.

and the patient was discharged with a good general condition. The stent was removed 2 weeks later and no signs of hemorrhage were observed within 1-month follow-up period.

\section{What is your diagnosis?}

\section{Answer:}

Bleeding from the site of sphincterotomy is common especially in therapeutic ERCPs and mostly are self-limited. In the present case, severe and refractory bleeding seemed to be from an aberrant artery at the location of sphincterotomy.
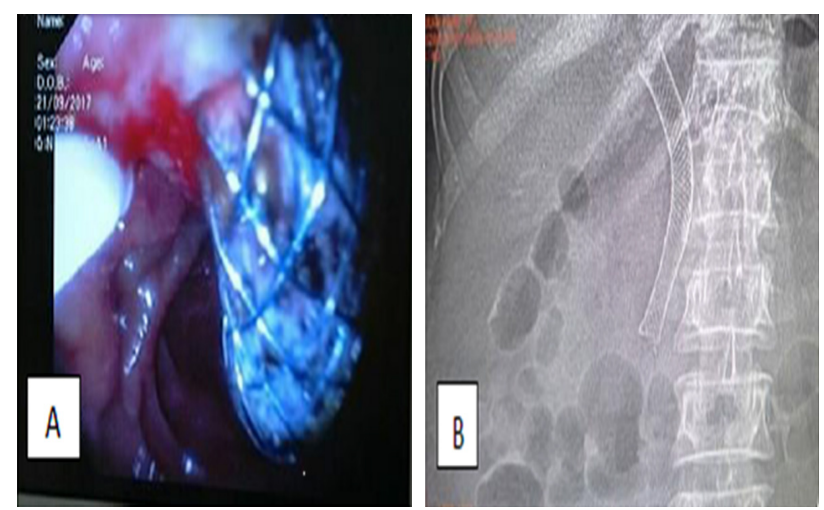

Fig.2: A and B: The stent that was used to control bleeding.

\section{DISCUSSION}

In multivariant studies, risk factors for the post ERCP bleeding are defined as: coagulative disorders (PT $>1.5$ $\mathrm{N}$ ), administration of anticoagulants within 72 hours before and after ERCP, hemodialysis, presence of an acute cholangitis or stenosis, precut sphincterotomy, and poor experience of the operator. ${ }^{1,2}$

Bleeding at the beginning of the operation may increase the possibility of latent bleeding. Presence of hepatic cirrhosis without coagulative disorder may not increase the probability of bleeding and administration of non-steroidal medicines plays no important role in the onset of bleeding. ${ }^{3,4}$ 
Precut sphincterotomy and papillary stenosis are independent risk factors. ${ }^{5}$ Moreover, zipper cut and needleknife sphincterotomy have been put forth as independent factors in a study carried out in Korea. ${ }^{6}$

Prevention of post ERCP bleeding includes identification of the patient's risk factors, being careful of the coagulative status of the patients, and accurate adoption of the proper ERCP methods. Post sphincterotomy bleeding may be self-limited. In case of a necessity for a primary therapeutic intervention, epinephrine with a concentration of 1:100000 may be sprayed at the location followed by injection with a concentration of $1: 10000$. In case of failure to stop bleeding, the next steps include: mechanical pressure with balloon, electrocautery, and APC. Angiography and surgical intervention are the last methods, if all previous interventions fail to control bleeding. ${ }^{7}$

\section{ACKNOWLEDGMENTS}

The authors acknowledge the Gastroenterology and Hepatology Disease Research Center for providing their support in writing the present report.

\section{ETHICAL APPROVAL}

There is nothing to be declared.

\section{CONFLICT OF INTEREST}

The authors declare no conflict of interest related to this work.

\section{REFERENCES}

1. Freeman ML, Nelson DB, Sherman S, Haber GB, Herman ME, Dorsher PJ,,et al. Complications of endoscopic biliary sphincterotomy. N Engl J Med 1996;26:335:909-18. doi: 10.1056/NEJM199609263351301.

2. Masci E, Toti G, Mariani A, Curioni S, Lomazzi A, Dinelli M,et al. Complications of diagnostic and therapeutic ERCP: a prospective multicenter study. Am J Gastroenterol 2001;96:417-23. doi:10.1111/j.1572-0241.2001.03594.x.

3. Loperfido S, Angelini G, Benedetti G, Chilovi F, Costan F, DeBerardinis F,et al. Major early complications from diagnostic andtherapeutic ERCP: a prospective multicenter study. Gastrointest Endosc 1998;48:1-10. doi:10.1016/ S0016-5107(98)70121-X.

4. Deenadayalu VP, Blaut U, Watkins JL, Barnett J, Freeman $\mathrm{M}$, Geenen J,et al. Does obesity confer an increased risk and/or more severe course of post-ERCP pancreatitis?: a retrospective, multicenter study. J Clin Gastroenterol 2008;42:1103-9. doi:10.1097/MCG.0b013e318159cbd1.

5. Yoo JW, Ryu JK, Lee SH, Woo SM, Park JK, Yoon WJ, et al. Preventive effects of ulinastatin on post-endoscopic retrograde cholangiopancreatography pancreatitis in high-risk patients: a prospective, randomized, placebocontrolled trial. Pancreas 2008;37:366-70. doi:10.1097/ MPA.0b013e31817f528f.

6. Ferreira LE, Baron TH. Post-sphincterotomy bleeding: who, what, when, and how. Am J Gastroenterol 2007;102:2850-8. doi:10.1111/j.1572-0241.2007.01563.x.

7. Freeman ML. Toward improving outcomes of ERCP. Gastrointest Endosc 1998;48:96-102. doi:10.1016/S00165107(98)70143-9. 